\title{
VIOLÊNCIA E DEMOCRACIA: O PARADOXO BRASILEIRO
}

Por Lourdes Bandeira

PERALVA, Angelina. Violência e democracia:

o paradoxo brasileiro. São Paulo : Paz e Terra, 2000.

Angelina Peralva nos introduz, ao titular seu livro, Violência e democracia: o paradoxo brasileiro, num dos principais dilemas em que vive a sociedade brasileira: ou seja, o retorno do Brasil à democracia caracterizado pelo crescimento intenso da violência, particularmente dos crimes de sangue, a partir de meados dos anos 80. Explicita como tal fato não impediu que a experiência democrática instalada produzisse o que denomina uma mutação igualitária.

Discute tal idéia a partir de uma base histórica e conceitual, centrando-se na noção de igualdade e de liberdade. Ultrapassa os sentidos estreitos de que a primeira se restringe à dimensão socioeconômica, antes a associa à experiência democrática, à idéia de uma lei comum, à qual todos deveriam imperativamente referir-se; quanto à segunda, a liberdade, foi se construindo simbolicamente no interior mesmo do regime militar, ainda nos últimos anos da década de 70. Seja através da vasta e complexa expressão dos movimentos sociais, que possibilitaram fôlego e visibilidade às chamadas minorias sociais e às diversidades culturais, atingindo o processo de legitimação, ainda que não plenamente, na Constituição de 1988; seja através da própria experiência democrática que, ao instalar-se, vai ocasionando mutações 
nas condições da consciência coletiva, bem como na reconfiguração do conflito social.

A liberdade teve impacto imediato sobre a igualdade, afirma, pois a base das distâncias, dos conflitos e das desigualdades sociais, mudaram. A abertura democrática no entanto, não se fez tão eficaz como desejada, pois, as reformas e mudanças nas instituições, nos processos de regulação social, bem como nas relações de poder, na ordem e esfera públicas não ocorreram a contento. Isto significou, segundo Peralva que, por um lado, "a democracia terminou abrindo amplas possibilidades para que a violência se desenvolvesse”, e por outro, "a sociedade brasileira manifestou um alto grau de tolerância e, em resposta, a violência produziu estratégias de adaptação e de ressegregação”.

O cenário empírico deste trabalho abrangeu as favelas da cidade de Rio de Janeiro, particularizando a juventude carioca pobre da favela Santa Marta, local cuja dinâmica da violência e do crime instalou-se com toda força, a partir da chegada do tráfico de drogas.

Assim, o propósito central da autora em Violência e democracia: o paradoxo brasileiro, é de refletir a partir das mudanças em relação a importância e ao papel que a violência e o crime assumem, na geografia pessoal e social da sociedade brasileira. Ao mesmo tempo, apontando novos conflitos e exacerbando outros tantos, demonstra como tal situação vem dificultando a capacidade dos diversos segmentos sociais de administrá-los. Peralva desdobra sua análise, em três partes.

Em A mutação igualitária, analisa o retorno do Brasil às práticas democráticas instaladas e os efeitos destas decorridos. A autora destaca tanto a vitalidade política que deu suporte à abertura democrática, quanto às contradições que tal processo ensejou. Ou seja, os percalços da economia, a eclosão das lutas populares e dos movimentos sociais, a emergência de novos espaços institucionais e políticos como a criação do partido dos trabalhadores (PT) e das três centrais sindicais; da organização dos camponeses sem terra (MST), da elaboração do Estatuto da Criança e do Adolescente, do Movimento Nacional dos Meninos e Meninas de Rua (MNMMR), da presença do Movimento Negro, extensivo à questão étnico/racial e às lutas de integração identitáriacultural; das diversas reivindicações em benefício da melhoria das 
condições de escolaridade, assim como das greves dos funcionários públicos, entre outros.

A especulação imobiliária, destaca, sobretudo no Rio de Janeiro, redesenhou a paisagem urbana e desencadeou uma forte reação nas camadas populares, ocasionando reações organizadas que, nas brechas da lei e do mercado, inventaram novos espaços habitáveis. Portanto, o processo que compreendia uma política de erradicação das favelas, acabou voltando-se a uma ampliação dos serviços urbanos de base, extensivos aos Guetos Voluntários. Segundo Peralva, os indicadores socioeconômicos sugerem que as favelas já não podem mais ser consideradas como o locus especifico da pobreza: a favela desceu o morro...

Enfim, as múltiplas mudanças ocorridas proporcionaram uma paisagem urbana - socioeconômica e cultural, - transformada que, por mais importante que sejam seus efeitos negativos, não impediu, por um lado, de continuar ignorando o impacto da mutação igualitária; por outro, recolocou em novos patamares os termos do conflito social. Em outros termos, as regras do jogo social mudaram, pois a interpenetração entre o universo do morro e o da classe média cresceu, seja porque não se trata mais de administrar as situações de exclusão, mas de administrar e de controlar o próprio processo de inclusão; seja porque a rua tornou-se o principal espaço de trocas e de encontros interrelacionais, fazendo do espaço público um lugar também de convivialidade e de lazer.

Por sua vez, a mídia, jogou um papel importante, ao constituir-se num poderoso meio de informação e de visibilidade, ao recolocar a favela no conjunto de sua dinâmica informacional muito embora não tenha se furtado a certos exageros a respeito das notícias sobre as atividades do narcotráfico na favela.

A família como a escola continuam tendo papéis fundamentais e estratégicos, afirma a autora; a primeira, estruturada, garante a dinâmica de solidariedade, a redução dos conflitos e a ampliação dos 
afetos, importantes para a configuração da identidade individual de seus membros. A segunda, ainda garante os mecanismos de mobilidade social, embora não de emprego, mas de ruptura com os limites da condição de ser favelado, pois a idéia de "que para ter sucesso na vida a escola e imprescindível esta mais presente entre os jovens do morro do que em relação aos adolescentes dos segmentos médios". Portanto, a escola exerce uma função reguladora, porque ainda garante a presença da diversidade e da alteridade social, o que a torna menos desigual e perceptível durante o seu funcionamento do que fora dela.

Os conflitos socioculturais também foram redesenhados e ressignificados, reiterando-os também como tensões e ambigüidades, Peralva, os resume como sendo os três grandes paradoxos que enfrentam os jovens cariocas favelados: "a escolha do horizonte futuro entre a vontade de ficar e a idéia de partir da favela; como construir, simultaneamente, a experiência da igualdade e do reconhecimento, e de uma diferença inscrita em uma história e memória pessoal? Como lidar com as situações de discriminação e de racismo, vividas de forma dramática, na experiência cotidiana, onde o apelo à diferença de raça neutraliza a possibilidade de uma igualdade objetiva, que se reconverte em desigualdade?"

Portanto, cada novo segmento identitário, que a seu modo, expressou os conflitos emergentes, cuja origem assentou-se na experiência do individualismo de massa, mantém, por sua vez, uma forma ainda incerta e se inscreve em um registro protopolítico, razão pela qual, segundo a autora, freqüentemente se confundem com a violência.

Em A espiral da criminalidade, expõe os legados do regime militar anterior que permitiu a exacerbação, no contexto urbano, de violências extremas. São quatro os eixos interpretativos investigados a propósito da escalada da violência e da criminalidade no Rio de Janeiro: primeiro, a continuidade autoritária, tratou do legado do regime autoritário precedente, refletido tanto nas instituições e na ordem pública como no interior da própria sociedade, cujos resquícios permaneceram fortemente durante o período de "transição" democrática (1979 a 1989), até a primeira eleição presidencial direta. Ora, tal legado obstaculizou, por um lado, qualquer tentativa de reforma nos quadros policiais, uma 
vez que o arbítrio policial não cessou com o fim do regime militar, e, por outro, pela criação da segurança privada.

Outro aspecto da continuidade autoritária, baseava-se na noção de autoritarismo socialmente implantado, via pela qual se tentava explicar, em termos de uma cultura política, o enraizamento de práticas violentas no seio da população. Muitos achavam que, para combater a criminalidade era necessário intensificar a repressão, admitindo também que uma violência com fins de autodefesa devesse ser diretamente exercida pela sociedade civil.

Portanto, o funcionamento autoritário, se fez presente, operando com altos índices da taxa de criminalidade que, nos anos 90, duplicaram os percentuais de homicídios no Brasil: em 1980, era de 11,68\% por 100 mil habitantes; passou para 25,37\% em 1997. É difícil explicar tais índices, pois a complexidade do processo de construção da democracia tem, como bem assinalou a autora, elementos de compreensão acumulados, registrados na memória social viva, particularmente as modalidades violentas de intervenção da polícia da ditadura, sobretudo em relação aos segmentos pobres da população. Com isso, o Estado aceitou e transferiu para a sociedade civil parte de uma violência que, até então, de algum modo, tinha exercido como sua responsabilidade e monopólio.

Os temas da delinquiência e da criminalidade foram introduzidos com grande alarde no debate público e a mídia não se fez de rogada, pois diante das falhas do Estado, não somente a violência urbana cresceu, mas passou a favorecer, mais do que nunca, a existência de um mercado de segurança privada, legal e ilegal. A espiral da violência estava lançada, conclui Peralva.

A desorganização das instituições responsáveis pela ordem pública acelera a escalada da violência no Rio de Janeiro e a desorganização do aparelho policial, e enfatiza o processo político democrático que sucedeu ao regime autoritário a partir das primeiras eleições para governadores estaduais. No Estado do Rio, com a vitória do governador Brizola, evidenciou o quanto o aparelho policial exigia mudanças profundas em relação à formação dos agentes policiais. 
Ao analisar a escalada da violência, registra que, em 1996, foi lançado o Programa Nacional de Direitos Humanos, cujos resultados não foram satisfatórios, pois a ineficiência do conjunto do aparelho policial e judiciário criaram dificuldades à defesa dos direitos humanos. Ao contrário, grandes violações destes foram cometidas, através da diversidade de práticas criminosas envolvendo diretamente policiais que se beneficiavam de cobertura institucional, uma vez que o regime autoritário, pela sua própria natureza, pressupunha a ausência de um conjunto de direitos.

Portanto, cabia à democracia dar respostas com base nos direitos sociais, uma vez que os demais - civis e políticos - eram então inexistentes. Na realidade, tais respostas não aconteceram.

Atribuir ou associar a violência e o crime à pobreza, não deixa de ser uma formulação simplista e mecânica, com a qual estamos bem de acordo com Peralva; mas, ao verificar seja a geografia das mortes violentas, seja a geografia das intervenções policiais, ou ainda as populações nas prisões, a associação entre crime e pobreza é incontornável, afirma a autora. Outras mediações históricas e culturais são daí derivativas, destacando as noções de revolta e de privação relativa, que reconstróem a relação entre crime e pobreza, ali mesmo, onde havia existido a vontade de negá-la. Portanto, a desigualdade socioeconômica se vê novamente imbricada na explicação do crime.

No entanto, a autora, nos conduz para muito além dessas explicações, pois o crescimento da violência e da criminalidade, no interior do processo que formou a democracia brasileira, é complexo e multifacético, no qual tanto pobres como ricos se encontram conjuntamente imbricados. O problema, enfatiza, é compreender melhor como os brasileiros co-produzem a violência de que são as próprias vitimas.

Por último, detém-se no impacto da mudança social, que seria $o$ de uma suposta relação entre o crescimento da criminalidade e a modernização cultural da sociedade brasileira. Parte da insuficiência do argumento que se fundamenta no desenvolvimento de um individualismo selvagem, que encontra na violência a sua expressão 
exacerbada. Avança, no sentido de destacar o valor da experiência dos jovens hoje, enfatizando a menor importância relativa do trabalho na estruturação da vida coletiva, o peso maior da educação nas escolhas individuais, mais participação no consumo de massa, entre outras, mudanças estas que tiveram um impacto significativo sobre o sentimento de igualdade.

A terceira parte, Face ao risco, compreende a história de Lúcio e a de Márcio. A análise dos dois estudos de caso evidencia a importância que assumem as condutas de risco e os vínculos existentes entre esse sentimento e uma nova conflitualidade urbana emergente. Ou seja, "risco e auto-realização individual tornam-se de algum modo sinônimos, a partir do momento em que a auto-realização pressupõe que o indivíduo se projete no futuro, sem que os resultados dessa projeção jamais sejam totalmente conhecidos", enfatiza a autora. Pois os ganhos em termos de individualização, com a abertura democrática, afetaram as formas de construção da confiança e da autonomia; a igualdade sociocultural democrática levou à decomposição das formas de estruturação do vínculo social que antes caracterizava o mundo popular, e esta efetuando a unificação das condições gerais de desenvolvimento de um individualismo de massa. Em outras palavras, enfatiza Peralva: "a igualdade democrática tornou menos nítidas as referências coletivas da identidade individual, cujo fundamento principal deixou de ser o trabalho. A integração à sociedade continua a ocorrer sob formas conflituosa, mas que já não são mais as mesmas do passado". Portanto, conclui, o trabalho, ligado à individuação o conflito, pode assumir diferentes expressões e formas, inclusive, violentas.

Por sua vez, o Estado, se por um lado, ainda instituído de expressão autoritária, impediu de ser reconhecido como garantia da igualdade perante a lei, por outro, a desorganização ainda reinante, enfatiza Peralva, "pôs-nos frente a frente com a circulação ilegal de armas de fogo, meio pelo qual rapidamente se passou dos fenômenos de incivilidade e dos conflitos interpessoais ao crime", gerando, nas grandes metrópoles brasileiras, um estado de guerra permanente; com isso a violência se generalizou amplamente.

Que razões explicam essa disponibilidade dos jovens para o crime? - pergunta-se a autora. O engajamento de parte significativa 
dos jovens favelados no narcotráfico parece estar ligado, em grande medida, a uma familiaridade com o risco. Risco fabricado no seu próprio mundo cotidiano com a convivência ou com o engajamento na experiência do narcotráfico, baseada na idéia de uma integração conflitiva aos quadros da experiência do individualismo de massa, constituindo-se na expressão de vivência de situações de risco eminentes.

As situações de interferência policial na luta com os traficantes, no Morro Santa Marta, são vistas como abusivas, seja porque os policiais agem com violência, invadem as casas, desrespeitam a população que habita a favela, criam situações de medo e de pânico; seja porque expõe de tal maneira os jovens diante da violência policial, desencadeando reações de revolta e resistências também violentas. Enfim, a autora demonstra bem como os jovens favelados estão cercados pela violência tantos dos narcotraficantes como dos policiais. Resume, dizendo: “a violência policial participa da construção da metáfora comunitária na favela. Ao acentuar a oposição entre os de dentro e os de fora, entre a favela e a cidade, atenuando por outro lado a oposição entre bandidos e moradores, a polícia reforça o que existe de patologia nesta metáfora".

Portanto, a experiência de risco e a ausência de ordem pública e legítima formatam as condutas e modelam as estratégias individuais de respostas ao risco, independentemente de valores, ou de aspirações a uma mobilidade social desviante. Lúcio, um trabalhador, alista-se no Comando Vermelho. É mobilizado tanto pelo ódio quanto pela indignação, falta de respeito e de reconhecimento; ou seja, pela total ausência de ordem pública na favela, para não perder sua casa e ter que renunciar definitivamente a viver na Santa Marta.

Márcio, por sua vez, deparou-se ainda jovem com o preconceito contra a sua condição de favelado. Seu engajamento no Comando Vermelho deveu-se a um conjunto de situações, mais do que a uma razão específica. A diferença em relação a Lúcio, que acabou abandonando o narcotráfico, e apela à identidade de trabalhador, ao desertar teve que enfrentar uma rejeição dupla, seja dos antigos companheiros da favela, seja dos próprios traficantes, é que Márcio se engajou definitivamente no Comando Vermelho. Fez de sua condição de traficante, em viver permanentemente em situação de risco, o seu 
lugar próprio de existência e de significado no mundo. Mais do que conviver com o risco, é a maneira de administrá-lo que lhe significa a existência.

A outra situação de risco analisada - o surfe ferroviário -, conseqüência da precariedade e da falta de segurança do sistema de transporte ferroviário, sobretudo no Rio de Janeiro e em São Paulo, onde a morte e a paisagem cotidiana do usuário de trens apresenta estatísticas de acidentes e de mortes que impressionam. "A juventude pobre, expõe seus corpos ao exercício do risco, controle e graça. Constituem elementos de uma interpretação geral de nossa sociedade aberta, altamente individualizada, e por isso mesmo portadora de necessidades crescentes em matéria de reflexividade", afirma a autora.

Ao concluir o livro, destaca que a redemocratização no Brasil trouxe consigo mudanças que transcenderam a esfera propriamente política. Acompanhadas pela violência generalizada, estão situadas na confluência de duas lógicas: a primeira, referindo-se às transformações no plano social e aos efeitos derivados, do ponto de vista de uma conflitualidade urbana de novo tipo; a outra, referindo-se à inépcia das instituições públicas e ao seu despreparo frente às novas exigências da vida democrática. Portanto, "trata-se muito mais da revolta, que expressa, sob formas embrionárias e não políticas, como as da incivilidade, um conflito em torno das condições gerais da individuação - conflito que reflete a busca de cada sujeito por um lugar próprio no mundo... cada um de nós passou a reagir mediante condutas de risco que provocaram uma espiral da violência”.

Todas as questões abordadas pela autora, representam um esforço para estimular a reflexão sociológica e a conscientização sobre novos e amplos horizontes conceituais, indicados, e que estão abertos para se pensar a violência, seja em relação à sociedade brasileira, seja no mundo contemporâneo. 


\section{Bibliografia francesa citada por Angelina Peralva:}

CAMUS, Albert. L'homme revolté. Paris : Gallimard, 1951.

CAPELLER, Wanda Lemos. L'engrenage de la repression: strategies securitaires et politiques criminelles, l'exemple du Bresil (1890-1990). Paris : LGDJ, 1995.

CHESNAIS, Jean-Claude. Histoire de la violence. Paris : Robert Laffont, 1981.

DUBET, Francois. La galere: jeunes en survie. Paris : Fayard, 1987.

EHERENBERG, Alain. Individus sous influence: drogues, alcools, medicaments psychotropes. Paris : Esprit, 1991.

FOUCAULT, Michel. La societe disciplinaire em crise. FOUCAULT, Michel. Dits et ecrits. Paris : Gallimard, 1994. v. 3.

PECAUT, Daniel. L'ordre et la violence: evolution socio-politique de la Colombie entre 1930 et 1953. Paris : Éditions de 1'École des Hautes Etudes en Sciences Sociales, 1987.

SENNETT, Richard. Les tyrannies de l'intimité. Paris : Seuil, 1979.

SINGLY, Francois de. Le soi, le couple et la famille.Paris : Nathan, 1996.

SINGLY, Francois de. Sociologie de la famille contemporaine. Paris : Nanthan, 1993.

TABBONI, Simonetta. Le multiculturalisme et l'ambivalence de l'etrager: In: WIEVIORKA, Michel (Org.). Une societé fragmenteé? le multiculturalisme en debat. Paris : La Découverte, 1996.

TOCQUEVILLE, Alexis. De la democratie en Amerique. Paris : Gallimard, 1986. $2 \mathrm{v}$.

TOURAINE, Alain. Pourrons-nous vivre ensemble? egaux et differents. Paris : Fayard, 1997.

VIDAL, Dominique. La politique au quartier. Paris : Maison des Sciences de l'Homme, 1999.

WIEVIORKA, Michel. La democratie à l'epreuve: nationalisme, populisme, ethnicité. Paris : La Découverte, 1993. . Une societé fragmenté: le multiculturalisme en debat. Paris : La Découverte, 1996.

WIRTH, Loius. Le ghetto. Paris : Presses Universitaires de Grenoble, 1980. 